SIMPÓSIO DOS

PROFISSIONAIS DA UNICAMP

\section{AS DOAC̄̃̃ES DE COLECOÕES PESSOAIS E INSTITUCIONAIS COMO FERRAMENTA NA AMPLIAÇÃO DOS ACERVOS DAS BIBLIOTECAS}

IZABEL CRISTINA BARBOSA DOS SANTOS, CECÍLIA MARIA JORGE NICOLAU, PAULO ROBERTO DE OLIVEIRA, SANDRO BARBOSA DO CARMO

IFCH - INSTITUTO DE FILOSOFIA E CIENCIAS HUMANAS;BIBL - DIRETORIA DA BIBLIOTECA;BPT - PROCESSOS TECNICOS;

\title{
Introdução:
}

DOI: $10.20396 /$ sinteses.v0i7.10231

A Seção de Processamento Técnico da Biblioteca Octavio lanni - IFCH/Unicamp funciona como um verdadeiro bastidor da Biblioteca. Atualmente conta com 4 colaboradores ativos, sendo: 3 bibliotecários e um técnico-administrativo. Em sua gama de atividades e serviços, destaca-se o Recebimento de Doações que sempre foi muito recorrente e vem se intensificando nos últimos anos. Além disso, essa atividade é uma importante ferramenta para manter seu acervo vivo e de qualidade. As ações de captação e recebimento de importantes doações, sejam elas pessoais e/ou institucionais corroboram para um crescimento organizado tanto quantitativo quanto qualitativo.

\section{Metodologia:}

O recebimento das Doação de acervos é pautado em critérios e diretrizes definidos tanto pela Coordenadoria da Administração Geral, quanto pela Biblioteca, e é composto por muitas etapas que vão desde a pesquisa dos itens que compõem o conjunto dos materiais, visita técnica para avaliação do estado físico dos itens, pareceres, abertura de processo, o recebimento efetivo do material, catalogação, tombamento e preparo físico das obras.

\section{Resultados:}

Como resultado, após concluídas todas as etapas que compõe o recebimento dos acervos, a Biblioteca disponibiliza aos usuários o acesso a um conjunto de material informacional relevante e muitas vezes inédito. Esse novo material bibliográfico contribui tanto para o desenvolvimento das coleções quanto para as pesquisas desenvolvidas pela comunidade discente e docente da Universidade, bem como pesquisadores externos. Pode-se destacar que em 2018 foram recebidos dois importantes acervos pessoais, com aproximadamente 3.500 itens no total, ampliando as coleções nas temáticas de História da Arte, Xilogravura, Antropologia da Imagem, Fotografia, Sociedades Indígenas, Teologia, Filosofia entre outras.

\section{Considerações finais:}

É importante manter ações que viabilizem a captação desses acervos para que a Biblioteca possa continuar a atender e receber as demandas referentes às intenções de doações pessoais e/ou institucionais, pois estas são sem dúvida, de suma importância para manter o nível de excelência do acervo da Biblioteca, que é considerado um dos maiores e mais importantes da América Latina na área de humanidades.

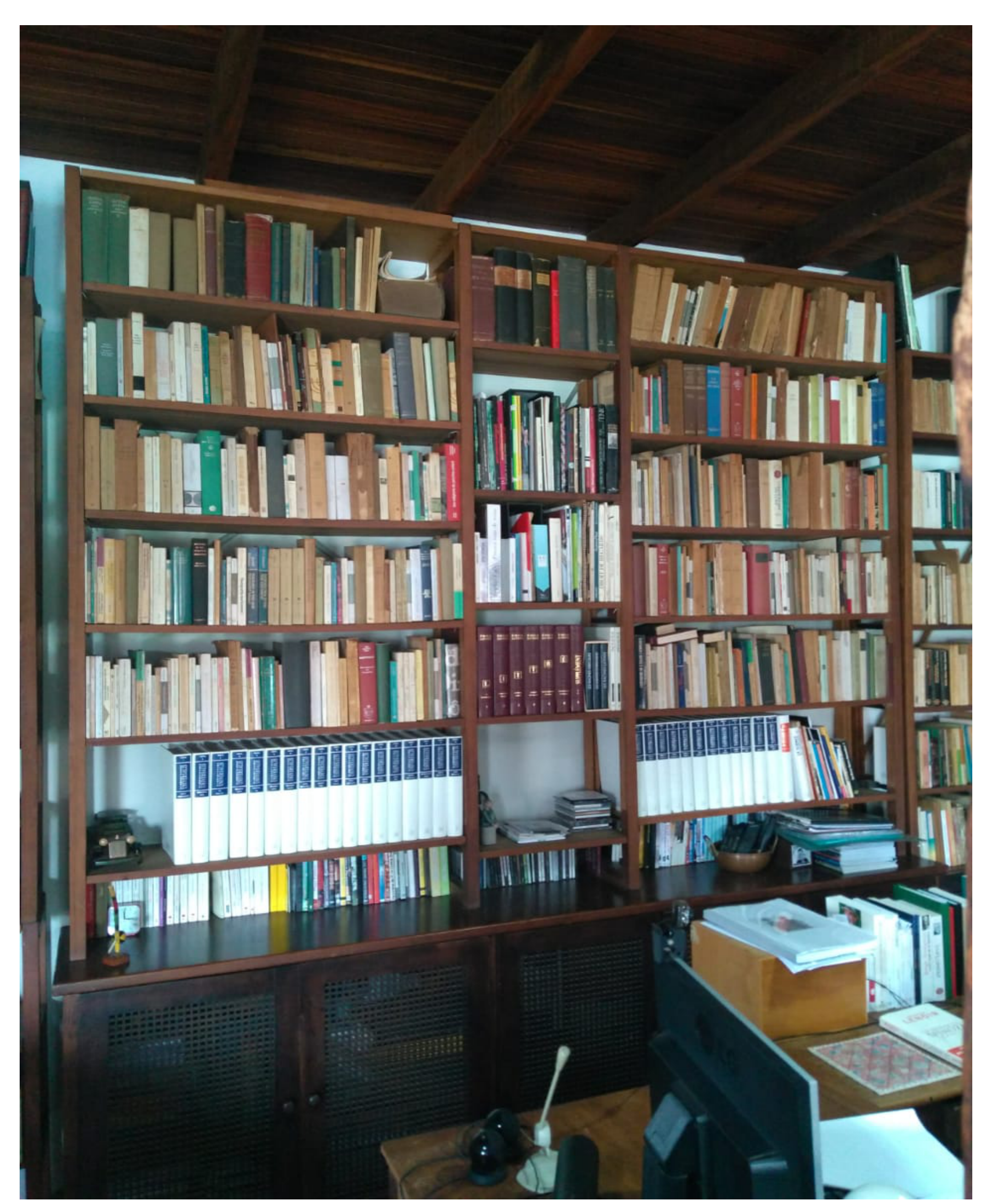

Parte do Acervo do Prof. Etienne Samain (novembro/2018)

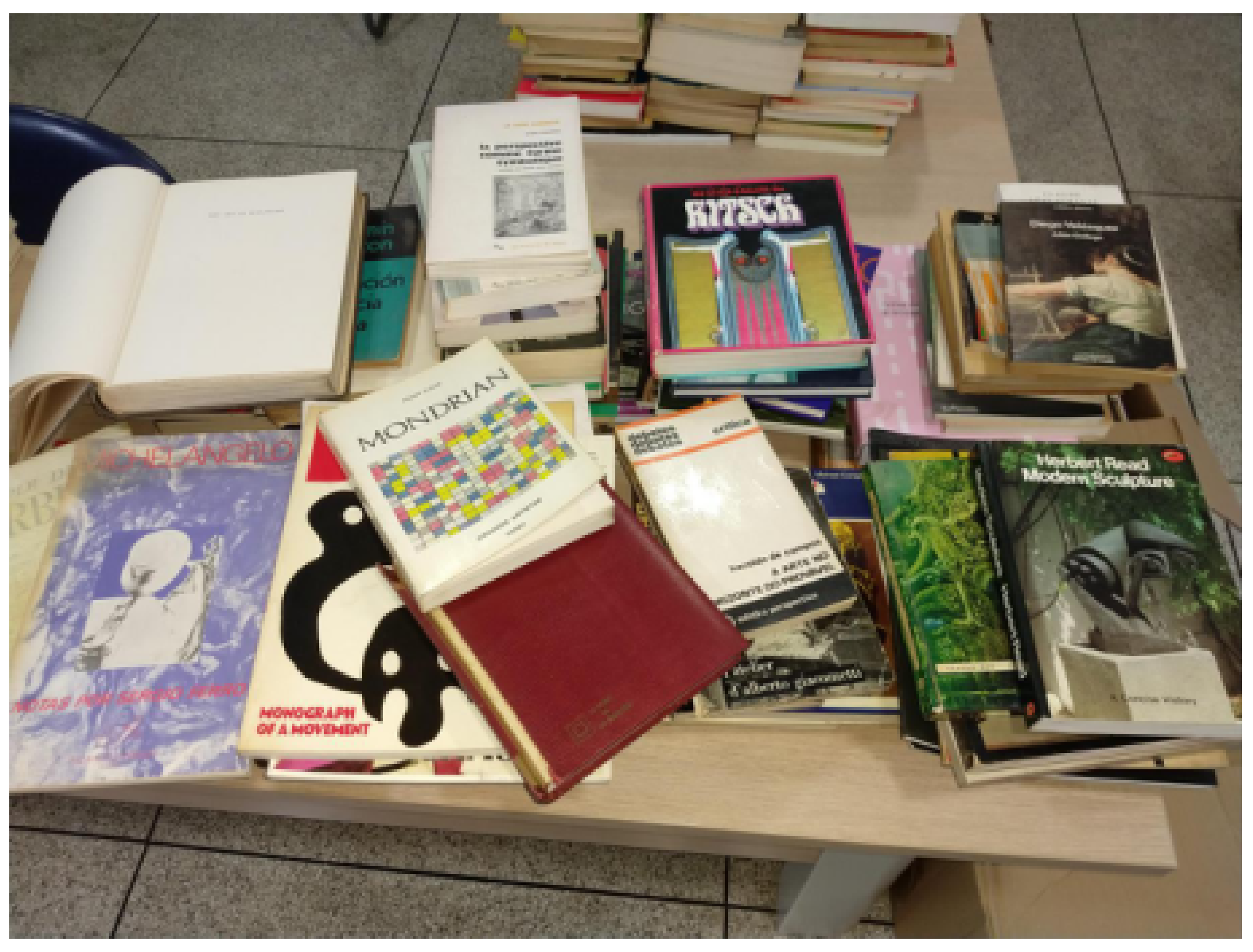

Parte do Acervo da Profa. Renina Katz (setembro/2018)

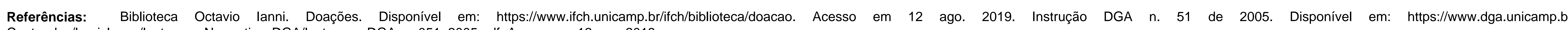
Conteudos/Legislacao/IIstrucoesNormativasDGA/Instrucao_DGA_n_051_2005.pdf. Acesso em 12 ago. 2019.

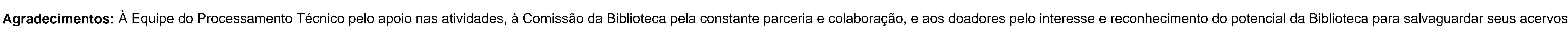

